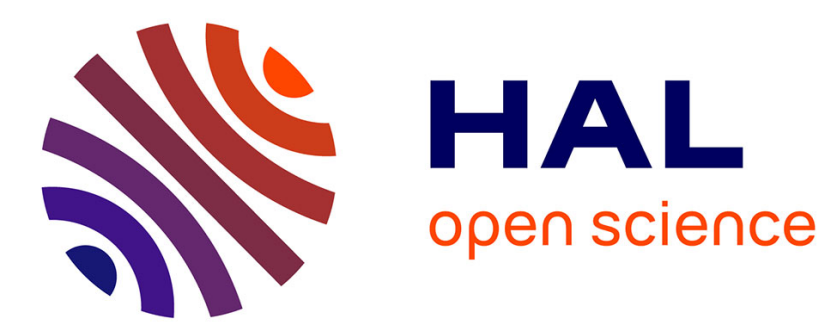

\title{
Platinum Nanoparticle Impacts at a Liquid/Liquid Interface
}

Talia Jane Stockmann, Leo Angele, Vitor Brasiliense, Catherine Combellas, Frederic Kanoufi

\section{> To cite this version:}

Talia Jane Stockmann, Leo Angele, Vitor Brasiliense, Catherine Combellas, Frederic Kanoufi. Platinum Nanoparticle Impacts at a Liquid/Liquid Interface. Angewandte Chemie International Edition, 2017, 56 (43), pp.13493-13497. 10.1002/anie.201707589 . hal-01767804

\section{HAL Id: hal-01767804 \\ https: / hal-univ-paris.archives-ouvertes.fr/hal-01767804}

Submitted on 24 Apr 2018

HAL is a multi-disciplinary open access archive for the deposit and dissemination of scientific research documents, whether they are published or not. The documents may come from teaching and research institutions in France or abroad, or from public or private research centers.
L'archive ouverte pluridisciplinaire HAL, est destinée au dépôt et à la diffusion de documents scientifiques de niveau recherche, publiés ou non, émanant des établissements d'enseignement et de recherche français ou étrangers, des laboratoires publics ou privés. 


\title{
Platinum nanoparticle impacts at a liquid|liquid interface
}

T. Jane Stockmann,* Léo Angelé, Vitor Brasiliense, Catherine Combellas, Frédéric Kanoufi*

Sorbonne Paris Cité, Paris Diderot University, Interfaces, Traitements, Organisation et Dynamique des Systèmes, CNRS-UMR 7086, 15 rue J. A. Baif, 75013 Paris - France.

To whom correspondence should be addressed: E-mail: frederic.kanoufi@univ-parisdiderot.fr; E-mail: jane.stockmann@univ-paris-diderot.fr

Key words: Nanoparticles, impacts, $\mathrm{O}_{2}$ reduction, bipolar, liquid|liquid interface

\begin{abstract}
Single nanoparticle (NP) electrochemistry detection at a micro liquid|liquid interface (LLI) is exploited through the oxygen reduction reaction (ORR) catalysis. In this way, current spikes reminiscent of nano-impacts were recorded owing to electrocatalytic enhancement of the ORR by Pt-NPs. The nature of the LLI provides the exploration of new phenomena in single NP electrochemistry. The current impacts are due to a bipolar reaction occurring at the Pt-NP straddling the LLI: $\mathrm{O}_{2}$ reduction takes place in the aqueous phase, while ferrocene hydride $\left(\mathrm{Fc}-\mathrm{H}^{+}\right)$, a complex generated upon facilitated interfacial proton transfer by Fc, is oxidized in the organic phase. Ultimately, the role of reactant partitioning, NP bouncing, or their ability to induce Marangoni effects are evidenced.
\end{abstract}




\section{Body}

The understanding of charge transfer processes at the nanoscale has been fueled by the emergence of single NP studies, such as electrochemical nanoimpact experiments, where insight into the reactivity of a NP is gained from the electrochemical detection of the collision of individual NPs onto a polarized microelectrode. ${ }^{[1]}$ However such studies, recently reviewed by Compton et al., ${ }^{[1 \mathrm{a}]}$ as well as by Robbs and Rees, ${ }^{[1 \mathrm{~b}]}$ are complicated by a rigorous control of the microelectrode detector surface chemistry and activity. The polarized interface between two immiscible liquids or electrolytes (ITIES) offers a more reproducible electrochemical soft-interface. Moreover, the use of nanoparticles (NPs) for catalysis at a polarized liquid|liquid interface (LLI), between water (w) and oil (o), particularly for the case of the oxygen reduction reaction (ORR), has gained prevalence. ${ }^{[2]}$ The ORR is then controlled by modification of the Galvani potential difference across the ITIES: $\phi_{w}-\phi_{o}=\Delta_{o}^{w} \phi$, while NPs enhance the reaction by effectively behaving as multivalent redox species, or electron reservoirs. ${ }^{[2 c, 3]}$ Single entity studies with immiscible liquid systems are few. Ensemble polarographic measurements of $\mathrm{TiO}_{2}, \mathrm{SnO}_{2}$, and $\mathrm{Fe}_{2} \mathrm{O}_{3}$ nanoparticles at renewed $\mathrm{Hg}$ droplet electrodes were first performed by Heyrovsky et al. ${ }^{[4]}$ Later, the group of Scholz investigated soft matter microparticle impacts, such as liposomes ${ }^{[5]}$ and vesicles/organelles, ${ }^{[6]}$ at a $\mathrm{Hg}$ electrode. These were expanded upon using solid ultramicroelectrodes (UMEs) to investigate nanodroplet impacts. ${ }^{[7]}$ Laborda et al. ${ }^{[8]}$ recently reported on single emulsion fusion events triggering a large flux of ions at a macro w|o interface and generating a spike-shaped current similar to the destructive impacts of metal-NPs. ${ }^{[1 \mathrm{f}, 9]}$ However, the study of metal-NP impacts at LLIs only concerns those at liquid $\mathrm{Hg} / \mathrm{Pt}$ UMEs or dropping $\mathrm{Hg}$ electrodes. ${ }^{[4,10]} \mathrm{We}$ propose herein to transpose the concept of electrochemical nanoimpact to a water|1,2dichloroethane (w|DCE) soft interface for the case of the catalytic activation of the ORR by Pt-NPs as illustrated in Scheme 1.

For this purpose, a microITIES platform $(25 \mu \mathrm{m}$ diameter) housed at the tip of a pulled borosilicate glass capillary was employed. $\mathrm{O}_{2}$ reduction is catalyzed by Pt-NPs present in w, using ferrocene $(\mathrm{Fc})$ as a sacrificial electron donor in $\mathrm{o}$, and $\mathrm{H}_{2} \mathrm{SO}_{4}$ as the proton source/supporting electrolyte in $\mathrm{w}$.

The system was first analyzed without Pt-NPs and with $5 \mathrm{mM}$ of $\mathrm{H}_{2} \mathrm{SO}_{4}$ added to w. In the absence of Fc in o (trace a in Figure 1A), the potential window is limited on either end by the transfer of the supporting electrolyte ions: $\mathrm{H}^{+}$and $\mathrm{HSO}_{4}^{-}$or $\mathrm{SO}_{4}^{2-}$ at positive and negative 
potentials, ${ }^{[11]}$ respectively. After addition of $50 \mathrm{mM}$ Fc to the DCE phase (trace $\mathrm{b}$ in Figure 1A), a peak-shaped wave was observed at $-0.150 \mathrm{~V}$. As the Fc concentration was increased the half-wave potential $\left(\Delta_{o}^{w} \phi_{1 / 2}\right)$ shifted towards more negative potentials while the peak current remained the same. This is indicative of facilitated ion transfer (FIT) ${ }^{[12]}$ of $\mathrm{H}^{+}$by Fc. Variation in half-wave transfer potential, $\Delta_{o}^{w} \phi_{\mathrm{Fc}-\mathrm{H}^{+}, 1 / 2}$ with the $\mathrm{Fc}$ bulk concentration, $c_{\mathrm{Fc}}^{*}$, (Figure 1B) suggests the FIT produces a $(1: 1)$ metallocene-hydride complex $\mathrm{Fc}_{-} \mathrm{H}^{+}$at a $\beta$ value of $4.2 \times 10^{12} \mathrm{~L} \mathrm{~mol}^{-1}$. This agrees with recent soft interfacial FIT studies. ${ }^{[12 \mathrm{c}, 12 \mathrm{~g}]}$

Since Fc can catalyze $\mathrm{O}_{2}$ reduction itself, although slowly, the slight negative baseline shift for the red trace in Figure 1A is likely due to $\mathrm{Fc}^{+}$transfer from $\mathrm{o} \rightarrow \mathrm{w}$, which becomes noticeable at the high $[\mathrm{Fc}]$ used here.

After addition of Pt-NPs, chronoamperograms (CAs) were recorded at $0.20 \mathrm{~V}$, after the FIT wave. Figures 2 A-C depict the CAs recorded using 5, 30, and 50nm diameter citrate capped Pt-NPs in $\mathrm{w}\left(1.6 \times 10^{11} \mathrm{NP} \mathrm{L}^{-1}\right)$; D shows the response with no NPs added. Once NPs are added, current spikes are observed reminiscent of electrocatalytic nanoimpacts of Pt-NPs at metallic UMEs. ${ }^{[1 \mathrm{c}-\mathrm{f}, 9 \mathrm{~b}, 9 \mathrm{c}, 13]}$ This suggests the spikes are related to Pt-NP impacts at the w/o microinterface. Owing to the charge convention at a LLI, the positive spikes could either be a positive charge transfer from $\mathrm{w} \rightarrow \mathrm{o}$ or a negative one from $\mathrm{o} \rightarrow \mathrm{w}$. The latter is consistent with electrons passed from $\mathrm{o} \rightarrow \mathrm{w}$, as illustrated in Scheme 1, where the NP catalyses the ORR in a bipolar electron transfer mode. Samec et al. ${ }^{[14]}$ electrochemically synthesized Pt-NPs at a macro w|o interface creating a nanofilm and proposed a similar interfacial NP catalysed electron transfer reaction, where decamethylferrocene acts as the electron donor.

No current spikes were observed at potential steps recorded before the FIT wave $(\leq-$ $0.20 \mathrm{~V}$ ) indicating that here the hydride $\mathrm{Fc}-\mathrm{H}^{+}$is the electron donor and that the NP catalyses the combined two interfacial reactions:

$$
\begin{aligned}
& \mathrm{Fc}-\mathrm{H}_{o}^{+} \rightarrow \mathrm{Fc}_{o}^{+}+\mathrm{H}_{o}^{+}+e^{-} \\
& 2 \mathrm{H}_{w}^{+}+\mathrm{O}_{2, w}+2 e^{-} \rightarrow \mathrm{H}_{2} \mathrm{O}_{2, w}
\end{aligned}
$$

The standard redox potential for Fc oxidation in DCE is $0.640 \mathrm{~V}^{[15]}$, while for (2) $E^{o}=$ $0.695 \mathrm{~V} .{ }^{[16]}$ The standard potential of the combined interfacial redox reaction: ${ }^{[14]}$

$$
E^{o \prime}=E_{F C^{+} / F C}^{o}-E_{O_{2} / H_{2} O_{2}}^{0}+0.059 \mathrm{pH}
$$


is then $E^{o \prime}=0.081 \mathrm{~V}$ which has a limited driving force at the applied potential $\left(\Delta_{o}^{w} \phi_{1 / 2}>0.2 \mathrm{~V}\right)$. It is enhanced with the hydride $\mathrm{Fc}-\mathrm{H}^{+}$, an activated form of $\mathrm{Fc}$, which likely has a higher $E^{o}$.

The form of the spikes detected, see inset in Figure 2, consists of three regions, as described recently by Stevenson et al. ${ }^{[10 \mathrm{a}, 10 \mathrm{~b}]}$ for Pt NPs at a Hg/Pt UME and Compton et al. ${ }^{[10 \mathrm{c}]}$ for $\mathrm{Hg}_{2} \mathrm{Cl}_{2}$ NPs at a $\mathrm{Hg} /$ carbon UME: (i) a period before impact with no catalysis (baseline),(ii) a sudden onset catalytic current when the NP collides, and (iii) a seconds-long current decay. The latter suggests a deactivation of the NP active surface, either by displacement of the citrate capping agent by $\mathrm{Fc}^{+}$, or from the action of reactive oxygen species produced during the ORR.

The liquid tube (of height $L \sim 150 \mu \mathrm{m}$ and radius $a$ ) restricts NP diffusion toward the LLI. Moreover, this restricted volume, $\sim 23 \mathrm{pL}$, contains (under Figure 2 conditions) $\sim 4$ NPs and allows the visualisation of single entity behaviour - especially for slowly diffusing entities. For example, the CA in Figure S1 shows two sets of multiple peaks: (i) a doublet at 45 and $47 \mathrm{~s}$ and (ii) 3 large current spikes at $\mathrm{t}>82 \mathrm{~s}$ within $40 \mathrm{~s}$. Owing to their uniform intensity (resp. 150 and 600pA) and residency time (resp. 1 and 2.5s), it can be assumed that each multiplet corresponds to the same large cluster/aggregate of 30nm diameter NPs bouncing on the LLI. Such bouncing also likely occurs for individual NPs, but the knowledge of their diffusion coefficient and concentration, $D_{N P}$ and $c_{N P}$ respectively, allows predicting the frequency of impacts $f$ from the equation of NP diffusive flux in the liquid tube through:

$f=\left(D_{N P} c_{N P} \pi a^{2}\right) /(a+L)$

Using Stokes-Einstein estimates of $D_{N P}$ for the 5, 30 and 50nm diameter NPs, respectively, for $c_{N P}=1.6 \times 10^{11} \mathrm{NP} \mathrm{L}^{-1}$ in Figure 2, one predicts $\sim 4,0.67$ and 0.4 current spikes per 100s. Spikes were selected, based on the above spike profile and excluding clusters, within a range of 8-100pA. Additional CAs can be found in the SI. Averaging over 10 CAs of 120s each, yields $2.5,1$, and 0.7 impacts per 100s, respectively. The concentration of the $30 \mathrm{~nm}$ NPs was changed from 1.6 to 7.0 and $16.0 \times 10^{11} \mathrm{NP} \mathrm{L}^{-1}$ giving $f \sim 2.6$ and 8.0 impacts per $100 \mathrm{~s}$ ( 3 and 6.7 predicted resp.). If the observed frequency of impacts is in general agreement with the predicted flux of NPs to the interface, the occurrence of frequent spikes, even with lower current amplitude, detected for the largest 30 and $50 \mathrm{~nm}$ NPs (Figure 2B,C) could indicate NP rolling/bouncing or physical perturbation of the LLI owing to the presence of the NP. In this 
way, NPs may instigate Marangoni-type instabilities, generated by rapid local changes in surface tension within the back-to-back double layers upon adsorption.

Further evidence of Marangoni instabilities induced by NP electrochemistry were sought through successive positive/negative potential stimulation (large changes in interfacial tension) of the LLI in the presence of NPs. Figure 3 shows the CA traces recorded at potentials more negative than the FIT peak $(\leq-0.20 \mathrm{~V})$. In trace A, obtained before any CA curve was recorded in the positive region, no current spike was observed. However, after CAs were performed at positive potentials (curves B-D), >100pA large negative current spikes were recorded. This suggests that Pt-NPs may form a film or 'islands' at the interface upon positive polarization, become deactivated, and then removed at negative potentials. These data are also reminiscent of recordings by Samec et al. ${ }^{[14]}$ via $\mathrm{CV}$ and Pt-NP film electrogenerated at a macroITIES.

Despite the possible aggregate formation, multiple bouncing, LLI deactivation process (and possible Marangoni effects) encountered, the observed catalytic current spikes were discussed more quantitatively. The histograms of their amplitude are plotted in Figure 4A-C. Even if the presence of NP aggregates is suspected, ${ }^{[17]}$ the smaller current region of each histogram has been fitted using a log-normal distribution to establish average spike amplitudes - taken from the log-normal peak - of 10, 40, and 46pA for the 5, 30 and $50 \mathrm{~nm}$ particles, respectively.

The observed current amplitudes were rationalized by a Comsol 2D simulation (details in SI). As presented in Scheme 1, the model considered the two interfacial reactions (1) and (2) occurring on each electrolyte side of the NP interface. The bipolar condition ensures that the reaction is driven with equal diffusional flux on each NP side. Even though it may depend on the penetration of the NP in the organic phase (see NP positions in Figure S7), a situation explored for solid sphere-cap electrodes resting on a plane,${ }^{[18]}$ here we explore the situation of one hemisphere placed in each phase. The simulation predicts the concentration profiles (Figure $\mathrm{S} 5$ for $\mathrm{O}_{2, w}$ ) and flux (or equivalent current flow at the ITIES) for the consumption of each reactant. Particularly (see Figure S6) the availability of $\mathrm{O}_{2}$ in the organic phase and its partitioning, allows local feeding of the aqueous phase and increase of $\mathrm{O}_{2, \mathrm{w}}$ mass-transfer at the NP-water interface. Based on the simulation, the simulated steady-state current $\left(i_{\text {lim }}\right)$ is limited by $\mathrm{O}_{2, \mathrm{w}}$ and values of 4,26 , and $43 \mathrm{pA}$ were estimated for the 5, 30, and 50nm NPs respectively, which are in fair agreement with the experimental values. 
The limiting current decreases when a larger portion of the NP is present in the DCE phase (subhemisphere). In the reverse situation (superhemisphere) higher currents are expected if, still in a bipolar fashion, $\mathrm{O}_{2}$ is reduced at the superhemispherical surface, while $\mathrm{Fc}-\mathrm{H}^{+}$oxidation occurs in the LLI ideally polarized at the same potential as the lower cap of the NP, present or contacting the DCE phase. This extreme situation of a nanosphere sitting on the interface provides the highest $i_{\mathrm{lim}}$ for $\mathrm{O}_{2}$ reduction (see $\left[\mathrm{O}_{2}\right]_{\mathrm{w}}$ profiles in Figure S8). Simulated values, obtained with $\mathrm{O}_{2}$ partitioning are 6,37 and $61 \mathrm{pA}$ respectively for 5,30 and 50nm NPs. This suggests that the smallest NPs are sitting on the LLI, while the larger ones are likely penetrating the LLI.

This communication shows a proof of concept towards liquid|liquid interfacial NP detection/characterization through stochastic collisions that broadens the number of platforms upon which this technique can be employed, thereby, expanding the 'state-of-the-art'. Owing to the non-destructive nature and flexibility of the LLI, bouncing and/or rolling of NPs was observed, demonstrating deactivation then re-activation without overall NP catalytic activity loss. Furthermore, this method provides sensitive individual as well as ensemble NP information not possible for nanofilms synthesized in situ at the LLI. Since the LLI is much easier to fabricate/more reproducible, it could also replace carbon nanoelectrodes in doublebarrel multimode sensing ${ }^{[19]}$ which combines resistive pulse and NP impact analysis. The fair agreement between the simulated and observed spike amplitudes, along with the calculated and experimental impact frequencies, demonstrate the sensitivity of this method.

\section{Acknowledgements}

TJS is grateful to the European Commission for a H2020-MSCA-IF grant, project number DLV-708814.

\section{References}

[1]a)S. V. Sokolov, S. Eloul, E. Katelhon, C. Batchelor-McAuley, R. G. Compton, Phys. Chem. Chem. Phys. 2017, 19, 28-43; b)P. H. Robbs, N. V. Rees, Phys. Chem. Chem. Phys. 2016, 18, 24812-24819; c)X. Xiao, A. J. Bard, J. Am. Chem. Soc. 2007, 129, 9610-9612; d)X. Xiao, F.-R. F. Fan, J. Zhou, A. J. Bard, J. Am. Chem. Soc. 2008, 130, 16669-16677; e)Y.-G. Zhou, N. V. Rees, R. G. Compton, Angew. Chem. Int. Ed. 2011, 50, 4219-4221; f)V. Brasiliense, P. Berto, C. Combellas, G. Tessier, F. Kanoufi, Acc. Chem. Res. 2016, 49, $2049-2057$.

[2]a)E. Smirnov, P. Peljo, M. D. Scanlon, H. H. Girault, ACS Nano 2015, 9, 6565-6575; b)E. Smirnov, P. Peljo, M. D. Scanlon, H. H. Girault, Electrochim. Acta 2016, 197, 362-373; c)M. D. Scanlon, P. Peljo, M. A. Mendez, E. Smirnov, H. H. Girault, Chem. Sci. 2015, 6, 2705-2720; d)Y. Gründer, M. D. Fabian, S. G. Booth, D. Plana, D. J. Fermín, P. I. Hill, R. A. W. Dryfe, Electrochim. Acta 2013, 110, 809-815.

[3]B. Su, H. H. Girault, J. Phys. Chem. B 2005, 109, 11427-11431.

[4]a)M. Heyrovsky, J. Jirkovsky, M. Struplova-Bartackova, Langmuir 1995, 11, 4300-4308; b)M. Heyrovsky, J. Jirkovsky, M. Struplova-Bartackova, Langmuir 1995, 11, 4309-4312; c)M. Heyrovsky, J. Jirkovsky, B. R. Mueller, Langmuir 1995, 11, 4293-4299; d)M. Heyrovsky, J. Jirkovsky, Langmuir 1995, 11, 4288-4292.

[5]a)D. Hellberg, F. Scholz, F. Schubert, M. Lovrić, D. Omanović, V. A. Hernández, R. Thede, J. Phys. Chem. B 2005, 109, 14715-14726; b)D. Hellberg, F. Scholz, F. Schauer, W. Weitschies, Electrochem. Commun. 2002, 4, 305-309; c)V. Agmo Hernández, F. Scholz, Bioelectrochemistry 2008, 74, 149-156; d)V. Agmo Hernández, M. Hermes, A. Milchev, F. Scholz, J. Solid State Electrochem. 2008, 13, 639.

[6]V. Agmo Hernández, J. Niessen, F. Harnisch, S. Block, A. Greinacher, H. K. Kroemer, C. A. Helm, F. Scholz, Bioelectrochemistry 2008, 74, 210-216. 
[7]a)B.-K. Kim, J. Kim, A. J. Bard, J. Am. Chem. Soc. 2015, 137, 2343-2349; b)B.-K. Kim, A. Boika, J. Kim, J. E. Dick, A. J. Bard, J. Am. Chem. Soc. 2014, 136, 4849-4852; c)J. E. Dick, C. Renault, B.-K. Kim, A. J. Bard, Angew. Chem. Int. Ed. 2014, 53, 11859-11862; d)H. Zhang, L. Sepunaru, S. V. Sokolov, E. Laborda, C. Batchelor-McAuley, R. G. Compton, Phys. Chem. Chem. Phys. 2017, 19, 15662-15666; e)H. S. Toh, R. G. Compton, Chem. Sci. 2015, 6, 5053-5058; f)W. Cheng, R. G. Compton, Angew. Chem. Int. Ed. 2015, 54, 7082-7085.

[8]E. Laborda, A. Molina, V. F. Espín, F. Martínez-Ortiz, J. García de la Torre, R. G. Compton, Angew. Chem. Int. Ed. 2017, 56, 782-785.

[9]a)S. M. Oja, D. A. Robinson, N. J. Vitti, M. A. Edwards, Y. Liu, H. S. White, B. Zhang, J. Am. Chem. Soc. 2017, 139, 708-718; b)A. N. Patel, A. Martinez-Marrades, V. Brasiliense, D. Koshelev, M. Besbes, R. Kuszelewicz, C. Combellas, G. Tessier, F. Kanoufi, Nano Lett. 2015, 15, 6454-6463; c)V. Brasiliense, A. N. Patel, A. Martinez-Marrades, J. Shi, Y. Chen, C. Combellas, G. Tessier, F. Kanoufi, J. Am. Chem. Soc. 2016, 138, 3478-3483.

[10]a)R. Dasari, D. A. Robinson, K. J. Stevenson, J. Am. Chem. Soc. 2013, 135, 570-573; b)D. A. Robinson, A. M. Kondajji, A. D. Castañeda, R. Dasari, R. M. Crooks, K. J. Stevenson, J. Phys. Chem. Lett. 2016, 7, 2512-2517; c)T. R. Bartlett, C. Batchelor-McAuley, K. Tschulik, K. Jurkschat, R. G. Compton, ChemElectroChem 2015, 2, 522-528.

[11]a)T. J. Stockmann, R. Guterman, P. J. Ragogna, Z. Ding, Langmuir 2016, 32, 12966-12974; b)A. J. Olaya, M. A. Méndez, F. Cortes-Salazar, H. H. Girault, J. Electroanal. Chem. 2010, 644, 60-66.

[12]a)F. Reymond, G. Lagger, P.-A. Carrupt, H. H. Girault, J. Electroanal. Chem. 1998, 451, 59-76; b)M. Senda, T. Kakiuchi, T. Osaka, Electrochim. Acta 1991, 36, 253-262; c)T. J. Stockmann, J.-M. Noel, A. Abou-Hassan, C. Combellas, F. Kanoufi, J. Phys. Chem. C 2016, 120, 11977-11983; d)Y. Qiao, B. Zhang, X. Zhu, T. Ji, B. Li, Q. Li, E. Chen, Y. Shao, Electroanalysis 2013, 24, 1080-1084; e)P. Peljo, H. H. Girault, in Encyclopedia of Analytical Chemistry, John Wiley \& Sons, Ltd, 2012; f)S. Liu, Q. Li, Y. Shao, Chem. Soc. Rev. 2011, 40, 22362253; g)T. J. Stockmann, Y. Lu, J. Zhang, H. H. Girault, Z. Ding, Chem. Eur. J. 2011, 17, 13206-13216.

[13]J. Kim, A. J. Bard, J. Am. Chem. Soc. 2016, 138, 975-979.

[14]A. Trojánek, J. Langmaier, Z. Samec, Electrochem. Commun. 2006, 8, 475-481.

[15]D. J. Fermin, R. Lahtinen, in Liquid Interfaces In Chemical, Biological And Pharmaceutical Applications (Ed.: A. G. Volkov), Marcel Dekker, Inc., 2001.

[16]M. L'Her, in Encyclopedia of Electrochemistry, Wiley-VCH Verlag GmbH \& Co. KGaA, 2007.

[17]K. Shimizu, S. V. Sokolov, N. P. Young, R. G. Compton, Phys. Chem. Chem. Phys. 2017, 19, 3911-3921.

[18]L. C. R. Alfred, K. B. Oldham, J. Phys. Chem. 1996, 100, 2170-2177.

[19]N. Panday, G. Qian, X. Wang, S. Chang, P. Pandey, J. He, ACS Nano 2016, 10, 11237-11248.

\section{Figures and Schemes}

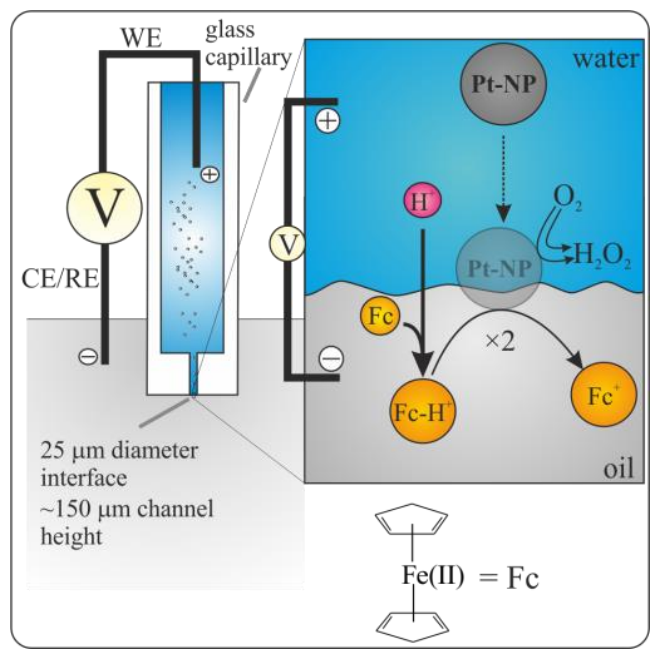

Scheme 1. Principle of $\mathrm{O}_{2}$ reduction using Pt-NPs and ferrocene $(\mathrm{Fc})$ as a sacrificial electron donor at a water|1,2-dichloroethane (w|DCE) interface (Cell 1). Electrolytes: $\mathrm{H}_{2} \mathrm{SO}_{4}$ in water, $\mathrm{P}_{8888} \mathrm{~TB}$ in DCE. 

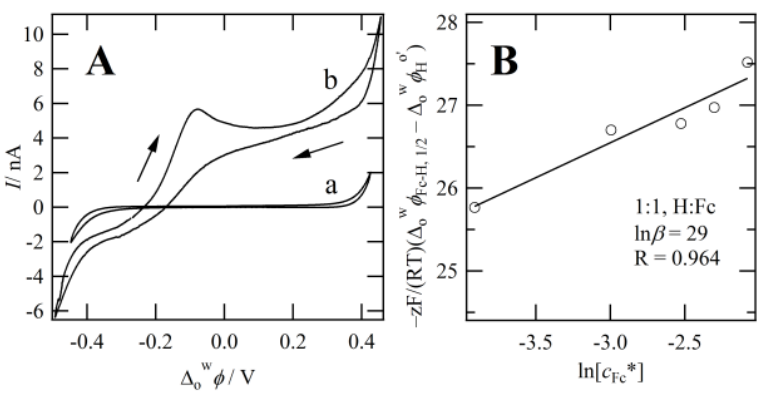

Figure 1. (A) Cyclic voltammograms in Cell 1 without (curve a) and with (curve b) $50 \mathrm{mM}$ ferrocene (Fc) with no NP added. (B) Trend of $-\frac{\mathrm{zF}}{\mathrm{RT}}\left(\Delta_{o}^{w} \phi_{\mathrm{Fc}-\mathrm{H}, 1 / 2}-\Delta_{o}^{w} \phi_{\mathrm{H}}^{o \prime}\right)$ versus $\ln \left[c_{\mathrm{Fc}}^{*}\right]$.

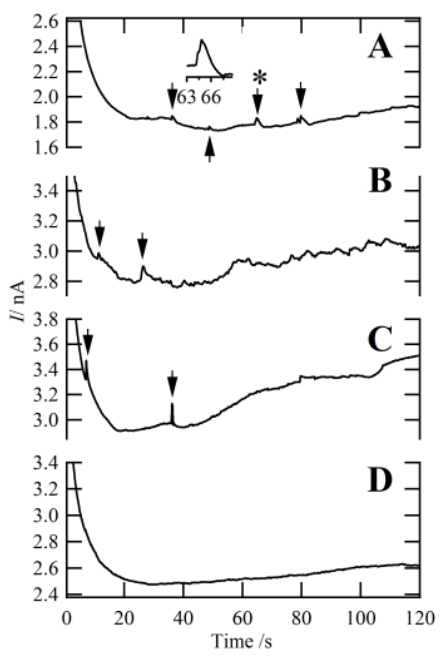

Figure 2: Chronoamperograms (CA) using Cell 1 ( $5 \mathrm{mM} \mathrm{Fc}$ ) with a potential step from -0.20 to $0.20 \mathrm{~V}$ with 5, 30, and 50nm diameter Pt-NP $\left(1.6 \times 10^{11} \mathrm{NP} \mathrm{L}^{-1}\right)$ for curves A-C, respectively (D: no NP added); inset is a typical current spike as marked with an *. Arrows: presumed current spikes. 


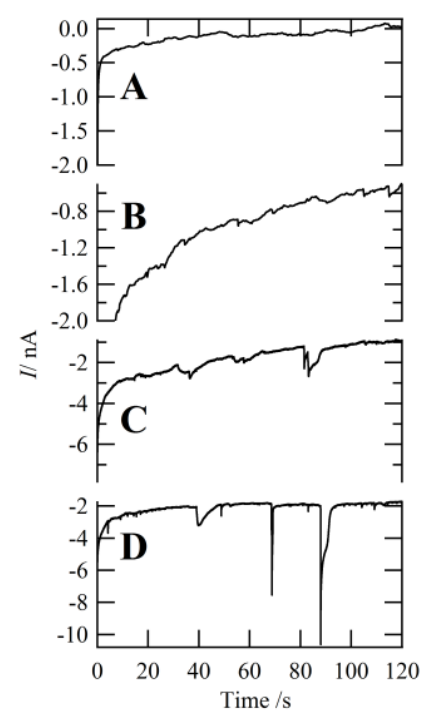

Figure 3 : Chronoamperograms (CAs) using Cell 1 (5mM Fc) with $5 \mathrm{~nm}$ diameter Pt-NPs dissolved at 1.6 (A and $\mathbf{B}), 7.0(\mathbf{C})$, and $16.0 \times 10^{11} \mathrm{NP} \mathrm{L}^{-1}(\mathbf{D})$ in the aqueous phase. A was recorded after a cyclic voltammogram was made to establish the polarizable potential window, but before any further positive polarization. Curves B-D were recorded after CAs were performed at positive potentials. CA potential steps were from -0.20 to $-0.30 \mathrm{~V}$.

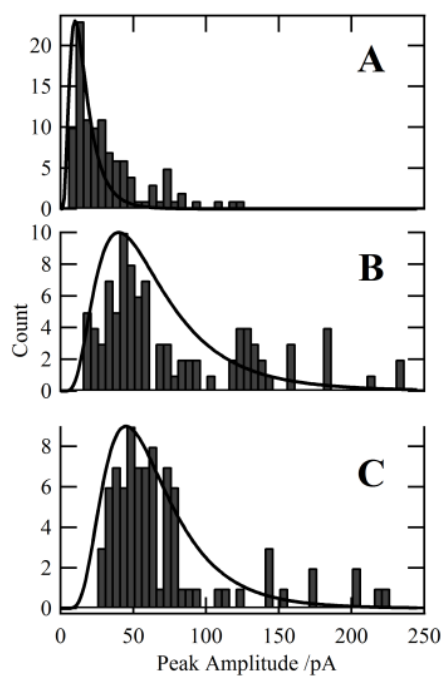

Figure 4: Histogram with log-normal trend (solid curve) of current spikes for (A) 5, (B) 30, and $(\mathrm{C}) 50 \mathrm{~nm}$ diameter Pt-NPs $\left([\mathrm{NP}]=1.6,7.0\right.$, and $\left.16.0 \times 10^{11} \mathrm{NP} \mathrm{L}^{-1}\right)$. 